\title{
Delimitación, clasificación y cartografía de los paisajes de la cuenca Ariguanabo, Cuba, mediante el uso de los SIG
}

\author{
Eduardo Salinas Chávez* \\ Alberto E. García* \\ Bárbara L. Miravet Sánchez ${ }^{* *}$ \\ Ricardo Remond Noa* \\ Elizabeth Cruañas López ${ }^{* *}$
}

\begin{abstract}
We intend to analyze the integrated landscape studies realized in Cuba for more than 40 years, showing in a particular study the elaboration of the Landscape Map' scale 1:25,000, using the Geographic Information System (GIS) tools and field expeditions supporting them. As result, a final landscape map of the Ariguanabo Basin was obtained, according to a diagnostic index. Four localities were differentiated, as well as 14 regions, some of which were subdivided later in 10 subregions according to karst presence and its grade of development.

Key words: Landscape map, Geographical Information Systems, Ariguanabo Basin.
\end{abstract}

\section{Resumen}

Nos proponemos analizar los estudios integrados del paisaje llevados a cabo en Cuba desde hace más de cuatro décadas, presentando en un caso particular la elabo-

* Facultad de Geografía, Universidad de la Habana, Edificio Mella \# Calle L, entre 21 y 23, Vedado, Playa, La Habana, Cuba, correos eléctrónicos: esalinas@geo.uh.cu; albertogarcia@geo.uh.cu; remond@geo.uh.cu

** Empresa de Ingeniería y Proyectos de la Electricidad, Calle 23 entre O y P núm. 105, Vedado, Playa, La Habana, Cuba, correos electrónicos: liz@inel.une.cu; ely@inel.une.cu 
ración del Mapa de paisajes a escala 1:25,000 con el uso de las herramientas de los Sistemas de Información Geográfica y el apoyo del trabajo de campo. Como resultado final se obtuvo un Mapa de paisajes de la cuenca Ariguanabo, donde de acuerdo a los índices diagnósticos utilizados se diferenciaron cuatro localidades, 14 comarcas, algunas de las cuales atendiendo a la presencia del carso y su grado de desarrollo fueron subdivididas en un total de 10 subcomarcas.

Palabras clave: Mapa de paisajes, Sistema de Información Geográfica, cuenca Ariguanabo.

\section{Introducción}

El paisaje geográfico o geosistema como categoría científica general de carácter transdisciplinario se concibe como "un sistema espacio-temporal, complejo y abierto, que se origina y evoluciona justamente en la interfase naturaleza-sociedad, en un constante estado de intercambio de energía, materia e información, donde su estructura, funcionamiento, dinámica y evolución reflejan la interacción entre los componentes naturales (abióticos y bióticos), técnico-económicos y socioculturales" (Mateo, 2008; Salinas, 1991 y NC 93-06-101).

Por el término de paisaje muchos investigadores y público en general entienden: naturaleza, territorio, área geográfica, medio ambiente, hábitat, escenario, etc. Sin embargo siempre que se hace referencia a una manifestación externa, a indicadores o procesos que corresponden al ámbito natural o humano se considera este término.

Los paisajes como unidades de integración de carácter holístico y sistémico constituyen la base para la realización de diversas investigaciones de carácter ambiental, que van desde la realización de los diagnósticos ambientales hasta el ordenamiento ambiental y territorial, concebido esto a partir del estudio de las propiedades y características de las unidades de paisajes, lo que permite proponer las formas de utilización más adecuadas bajo un enfoque de uso racional y diversificado (Bastian y Steinhardt, 2002; Bertrand y Bertrand, 2006; Busquet y Cortina, 2009 y Salinas et. al., 1993).

La Cartografía del paisaje puede y de hecho participa, en cada una de las fases de las investigaciones geoecológicas y ambientales, y en cada una de ellas se van a producir determinados tipos de mapas en función de la amplitud de los temas y del grado de generalización de sus contenidos.

El Mapa de paisaje está conceptuado como un mapa temático principal en el cual se representan las características fundamentales de los complejos territoriales naturales (Salitchev, 1979), siendo considerado el producto final de la etapa de caracterización, de este mapa principal se pueden derivar otros muy diversos que sirven de base o plataforma para cumplimentar el resto de las etapas del ordenamiento ambiental y territorial. 
Hoy en día existen diversos procedimientos para la realización de los mapas de paisajes, entre los cuales están aquellos que a partir del uso de los Sistemas de Información Geográfica (SIG) permiten la obtención de una tipificación del territorio según la manifestación de las relaciones entre los componentes naturales y la intervención humana, generando mapas preliminares en el gabinete que posteriormente son comprobados en el campo y se convierten en herramienta para la gestión del territorio.

\section{Los estudios de paisaje en Cuba}

Los estudios de los paisajes en Cuba comenzaron realmente con los trabajos realizados en el siglo XIX por Alejandro de Humboldt sobre la base del análisis de las relaciones existentes entre los diferentes componentes de la naturaleza, ya que los estudios realizados por otros investigadores en los siglos XVII y XVIII se habían limitado principalmente a la ubicación y descripción de los accidentes geográficos más sobresalientes de nuestro archipiélago.

Es a partir de estos importantes aportes realizados por el sabio alemán, que en el siglo XX un grupo de prestigiosos especialistas cubanos encabezados por el doctor Salvador Massip, promueven el conocimiento integral de la naturaleza cubana y sientan las bases para el inventario y cartografía de los diferentes componentes físico-geográficos del paisaje (relieve, clima, agua, suelos, etc.), realizados a partir de la década de los sesenta, y que culminan con la publicación en 1970 del Atlas Nacional de Cuba, que da inicio a una nueva etapa en los estudios físico-geográficos donde se promueve el análisis integral de la naturaleza y la creación en la década de los ochenta del Grupo de Investigaciones en Geoecología y Paisajes en la Facultad de Geografía de la Universidad de La Habana (Centro de Desarrollo Teóricometodológico de la Geografía Física Compleja o Geoecología en Cuba) lo que culmina en 1989 con la inclusión en el Nuevo Atlas Nacional de Cuba de la sección XII, dedicada a los paisajes (con 14 mapas a diversas escalas) y la realización en los años posteriores de más de 30 tesis de doctorado y maestría sobre la temática del paisaje como fundamento del ordenamiento de los territorios, así como numerosas investigaciones y publicaciones en Cuba y el extranjero, que han estado acompañadas de la impartición de numerosos cursos de posgrado y de conferencias por especialistas de este grupo en Cuba y diversos países de América Latina y Europa.

La concepción del paisaje como componente objetivo del territorio y recurso para su ordenación está presente en los estudios del Grupo de Geoecología y Paisajes de la Facultad de Geografía de la Universidad de La Habana desde los inicios de su constitución, y ha posibilitado establecer una plataforma teórico-metodológica y práctica importante para el ordenamiento territorial en Cuba, que se ha consolidado y extendido a otras instituciones desde hace más de una década. Incluso algunos especialistas en el ámbito internacional hablan de una Escuela Cubana del Paisaje, que recibió la influencia de las Escuelas de Paisaje de Europa Oriental en 
las décadas de los años sesenta y setenta del siglo pasado, que posteriormente asimiló y amplió sus relaciones con otras escuelas de Ecología de los Paisajes de Europa Occidental y Norteamérica.

Entre los estudios desarrollados por este grupo se pueden destacar: Mateo, J. (1979), quien presentó una clasificación de los paisajes de Cuba y un mapa de tipos de paisaje a escala 1:1,000,000; Salinas E. (1991) quien a partir de una amplia experiencia de trabajo en el análisis y evaluación de los paisajes a escalas grandes en diversos territorios de Cuba, estableció una serie de principios para la utilización de diferentes métodos en la evaluación de los paisajes como base para el ordenamiento territorial en Cuba. En 1995, Quintela J. estableció los fundamentos para el empleo de los Sistemas de Información Geográfica en las investigaciones geoecológicas, Acevedo P. quien en 1997 realizó un estudio detallado en la aplicación de diversos métodos para el análisis de los paisajes en el ejemplo del archipiélago SabanaCamagüey al norte de Cuba y por último Remond R. en el año 2003, que estudió la degradación de los paisajes de Cuba a tres niveles, nacional, provincial y municipal apoyándose en el empleo de la teledetección y los Sistemas de Información Geográfica. Finalmente como culminación de estos trabajos podemos mencionar la defensa del segundo doctorado de José Mateo en el año 2007, cuando a partir de sus trabajos, con el enfoque integrador del paisaje por más de dos décadas en Brasil y Cuba propuso una serie de fundamentos para una teoría geográfica de la sostenibilidad ambiental.

Además, se han llevado a cabo numerosos proyectos de investigación en Cuba y en otros países latinoamericanos donde, sobre la base de esta concepción integradora del paisaje, se han realizado los ordenamientos ecológicos y territoriales de diversas regiones y a diversas escalas, lo cual ha sido sustentado en los últimos años con el uso de los Sistemas de Información Geográfica (Salinas y Quintela, 2000; Ramón y Salinas, 2012; Ramón y Salinas, 2013) y jurídicamente detallado en 1997 con la aprobación de la Ley 81 de Medio Ambiente, donde se incluye por primera vez en Cuba el concepto de Ordenamiento Ambiental como rector de la Planificación y Gestión Ambiental, lo que se tradujo en la necesidad de elaborar un cuerpo teórico-metodológico adecuado para su realización, aspectos estos en los cuales a partir de la experiencia adquirida en estas últimas décadas, se trabaja actualmente (Gaceta Oficial de la República de Cuba, 1997).

En el ámbito docente desde hace tres décadas se imparte la asignatura de Geografía de los Paisajes en el tercer año de la licenciatura en Geografía en la Universidad de La Habana, como posgrado los profesores del grupo de Geoecología y Paisajes antes mencionado han impartido más de 200 cursos y seminarios a nivel de posgrado y decenas de conferencias en diversos países de América Latina y Europa, y desde el año 1995 coordinan la mención Paisajes y Planificación Ambiental de la maestría en Geografía, Medio Ambiente y Ordenamiento Territorial en la Facultad de Geografía e imparten además cursos sobre paisajes en más de 15 programas de maestría y doctorado en Cuba y el exterior. 
Actualmente nuestros especialistas asesoran más de 30 tesis de doctorado y maestría de especialistas cubanos y latinoamericanos y brindan entrenamientos de posgrado a colegas de otras instituciones y provincias de Cuba.

Como parte de la difusión de los resultados de las investigaciones que se realizan en Cuba desde hace más de tres décadas en este campo se han llevado a cabo cinco eventos internacionales sobre Geoecología y Paisajes (1993, 1997, 2002, 2007 y 2011) en los cuales han participado numerosos especialistas de gran prestigio de Cuba y el extranjero y se han presentado decenas de ponencias y conferencias.

Desde hace dos décadas dos profesores del grupo de Geoecología y Paisajes de la Facultad de Geografía de la Universidad de La Habana son miembros de la Asociación Internacional de Ecología del Paisaje (IALE) y han participado en diversos congresos de esta institución.

Finalmente se puede decir que se han publicado en Cuba y el exterior decenas de artículos, capítulos de libros y libros en ecología del paisaje y su aplicación al desarrollo de diferentes actividades socio-económicas.

\section{Delimitación, clasificación y cartografía de los paisajes de Cuba}

Esta se ha realizado a diferentes escalas y con diferentes enfoques (tipológico, regional y topológico o local) los cuales pueden resumirse de la manera siguiente:

Enfoque tipológico: los complejos naturales tipológicos se caracterizan por poseer rasgos comunes y propios no sólo de las unidades cercanas, sino también de otras alejadas. Son repetibles en el espacio y en el tiempo. Ellos se distinguen de acuerdo con los principios de analogía, homogeneidad relativa, pertenencia a un mismo tipo, repetibilidad y la existencia de muchos contornos con desunión areal de los mismos. El sistema de unidades taxonómicas utilizado en la clasificación de los paisajes de Cuba y de otros países de América Latina considera cuatro niveles taxonómicos, que son: clases, tipos, grupos y especies. Cada una de estas unidades se distingue según la asociación regular de los componentes naturales, mediante un grupo de índices diagnósticos. En el Mapa de los paisajes de Cuba a escala 1:1,000,000 fueron delimitados dos clases, cuatro tipos, 43 grupos y 84 especies (véase Figura 1).

Enfoque regional: consiste en delimitar unidades de carácter regional objetivamente existentes que se caracterizan por su irrepetibilidad o individualidad, de acuerdo con la estructura de los componentes, su composición sustancial, tanto cualitativa como cuantitativa, su integridad territorial, su unidad genética relativa, y su irrepetibilidad en el espacio y en el tiempo. Las unidades utilizadas en Cuba son: provincia, subprovincia, distrito y región, y fueron delimitadas en el mapa a escala 1:1,500,000 del Nuevo Atlas Nacional de Cuba del año 1989. Cuba constituye en- 
tonces una provincia físico-geográfica del subcontinente de América del Centro, con cuatro subprovincias, siete distritos y 48 regiones.

Enfoque topológico: a escalas detalladas y medias (1:10,000; 1:25,000; 1:50,000), se ha empleado la diferenciación y cartografía de las unidades topológicas o locales que sirven de base para estudios de ordenamiento territorial y ambiental detallados. Se han utilizado en Cuba en estos mapas tres unidades básicas en la diferenciación, que son: las localidades, definidas como un complejo natural genéticamente homogéneo, formado por la asociación de comarcas genéticamente relacionadas; las comarcas, unidad básica de la cartografía local de los paisajes; y las facies, que se consideran como la unidad más elemental, más pequeña y geográficamente indivisible (Mateo, Salinas y Guzmán, 1985; Salinas et al., 1993 y Ramón y Salinas, 2012).

\section{Los paisajes de la cuenca del río Ariguanabo}

La cuenca del río Ariguanabo tiene una extensión de $192.18 \mathrm{~km}^{2}$ y abarca parte de cuatro municipios: San Antonio de los Baños, Bauta, Caimito (provincia de Artemisa) y Bejucal (provincia de Mayabeque), con una población aproximada de unos 92,000 habitantes (Oficina Nacional de Estadísticas — ONE, 2011) (véase Figura 2).

La elaboración del Mapa de paisajes de la cuenca Ariguanabo nos ayuda a entender cómo se ha formado y trasformado el territorio, además de conocer la situación ambiental de la cuenca, que según diversos trabajos realizados es crítica, debido a la contaminación de sus aguas por el vertimiento de residuales líquidos y sólidos (urbanos, agropecuarios e industriales), la deforestación, la erosión y perdida de la fertilidad de los suelos entre otros problemas ambientales (GAMMA, 2007).

La cuenca constituye una de las principales fuentes de abasto de agua potable para las provincias de La Habana y Artemisa con un promedio anual de extracción de alrededor de 155 millones de metros cúbicos.

Las características del predominio del carso, su naturaleza de cuenca cerrada y su comunicación subterránea con la cuenca Vento-Almendares hacen de ella una cuenca de alta complejidad desde el punto de vista hidrogeológico, por lo cual ha sido incluida entre las cuencas de importancia nacional.

Para la confección del Mapa de paisaje de la cuenca Ariguanabo, lo primero que se realizó fue la selección de los índices diagnóstico para la clasificación de las unidades de paisajes que se detallan en las Tablas 1 y 2, los pisos altitudinales y rangos de inclinación de las pendientes utilizados. 


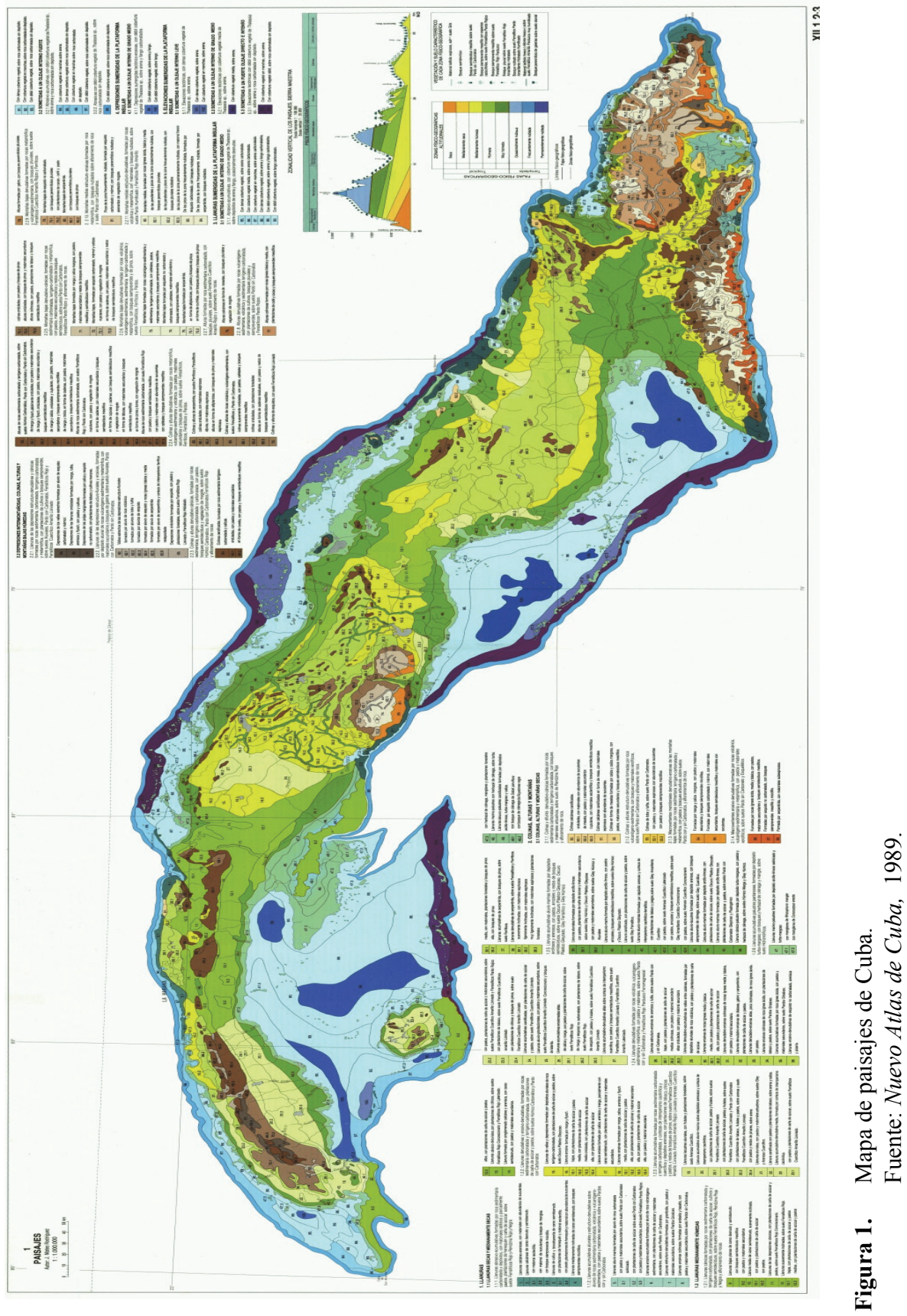




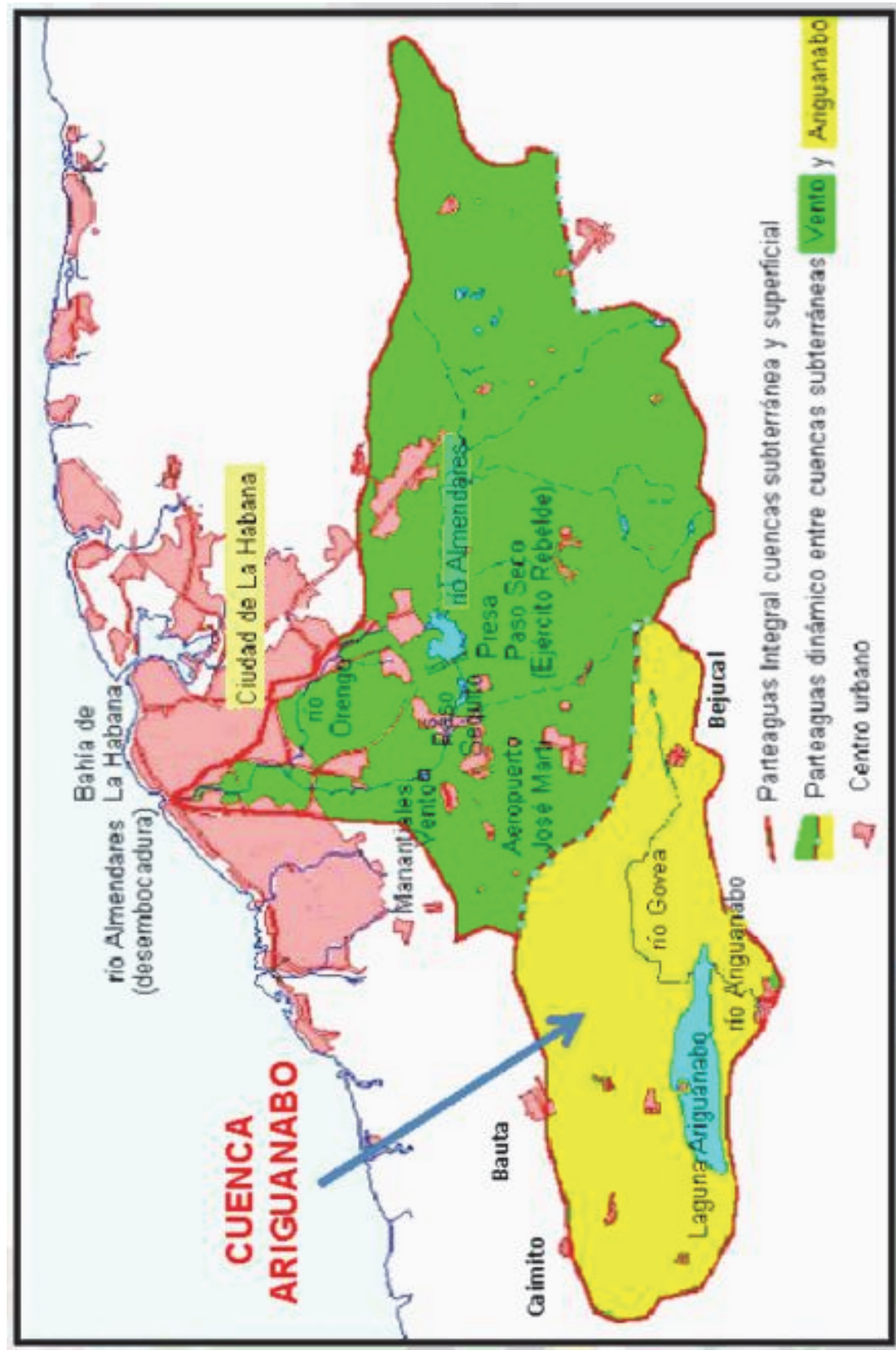

离 
Partiendo de las curvas de nivel con intervalo de $10 \mathrm{~m}$ se generó el modelo TIN y se convierte en raster (Figura 3). Se reclasifican las alturas y las pendientes de acuerdo a los rangos previamente establecidos, en el caso de las alturas se asumió la clasificación de pisos altitudinales de Hernández et al., 1986 (localidades) y para la inclinación de la pendiente se optó por utilizar los intervalos definidos en el Nuevo Atlas Nacional de Cuba (Figura 4). De este procesamiento se definieron cuatro unidades de paisaje de primer orden (denominadas en nuestro caso localidades).

Tabla 1

Índices diagnósticos de la unidades de paisajes

\begin{tabular}{|c|c|c|}
\hline Unidades & Índices diagnósticos & Ejemplo \\
\hline Localidad & $\begin{array}{l}\text { Asociación de determinados tipos de relieve } \\
\text { establecidos para el territorio nacional a partir de } \\
\text { los pisos altitudinales y los procesos de formación } \\
\text { del relieve: } \\
\text { - Llanuras medias } 45-80 \mathrm{~m} \\
\text { - Llanuras altas } 80-120 \mathrm{~m} \\
\text { - Alturas bajas } 120-200 \mathrm{~m} \\
\text { - Alturas medias } 200-260 \mathrm{~m} \\
\text { (Según Hernández et al., } 1986 \text { ) }\end{array}$ & $\begin{array}{l}\text { I-Llanuras medias } \\
(45-80 \mathrm{~m}) \text { cársico- } \\
\text { acumulativas de } \\
\text { planas a inclinadas }\end{array}$ \\
\hline Comarca & $\begin{array}{l}\text { Diferenciación en cuanto a la altura e inclinación } \\
\text { de las pendientes: } \\
\text { - Planas }\left(0-3^{0}\right) \\
\text { - Suavemente inclinadas }\left(3-5^{0}\right) \\
\text { - Inclinadas }\left(5-10^{0}\right) \\
\text { - Moderadamente inclinadas }\left(10-15^{0}\right) \\
\text { - Pendiente }\left(15-35^{0}\right) \\
\text { - Muy pendiente }\left(35-55^{0}\right) \\
\text { - Extremadamente pendiente }>55^{0} \\
\text { (Según Nuevo Atlas Nacional de Cuba, 1989) }\end{array}$ & $\begin{array}{l}\text { I3-Superficie plana } \\
\left(0-3^{0}\right)\end{array}$ \\
\hline Subcomarca & $\begin{array}{l}\text { Diferenciación en cuanto a la presencia y } \\
\text { desarrollo de los procesos cársicos: } \\
\text { - Carso desnudo y semi desnudo } \\
\text { - Carso cubierto por una delgada capa de suelo } \\
\text { - Carso estabilizado } \\
\text { - Carso cubierto por depósitos potentes } \\
\text { - Área no cársica }\end{array}$ & $\begin{array}{l}\text { I3b-Superficie plana } \\
\left(0-3^{0}\right) \text { con carso cu- } \\
\text { bierto por una delgada } \\
\text { capa de suelo }\end{array}$ \\
\hline
\end{tabular}

Fuente: Elaborada por los autores. 
Tabla 2

Pisos altitudinales y rangos de inclinación de las pendientes utilizados

\begin{tabular}{lclc}
\hline Pisos altitudinales & Altura $(m)$ & \multicolumn{1}{c}{$\begin{array}{c}\text { Rango de inclinación } \\
\text { de las pendientes }\end{array}$} & Inclinación $\left(^{\circ}\right)$ \\
\hline Llanuras medias & $45-80$ & Planas & $0-3$ \\
Llanuras altas & $80-120$ & Suavemente inclinadas & $3-5$ \\
Alturas bajas & $120-200$ & Inclinadas & $5-10$ \\
Alturas medias & $200-260$ & Moderadamente inclinadas & $10-15$ \\
& & Pendientes & $15-35$ \\
& & Muy pendientes & $35-55$ \\
& & Extremadamente pendientes & $>55$ \\
\hline
\end{tabular}

Fuente: Elaborada por los autores.

Se obtuvo el cruce inicial entre los pisos altitudinales e inclinación de la pendiente como se puede observar en la Tabla 3.

Tabla 3

Inclinación de las pendientes $\left({ }^{\circ}\right)$

\begin{tabular}{|c|c|c|c|c|c|c|c|c|c|c|c|c|c|c|c|c|}
\hline Pisos & \multicolumn{2}{|c|}{$0-3$} & \multicolumn{2}{|c|}{$3-5$} & \multicolumn{2}{|c|}{$5-10$} & \multicolumn{2}{|c|}{$10-15$} & \multicolumn{2}{|c|}{$15-35$} & \multicolumn{2}{|c|}{$35-55$} & \multicolumn{2}{|c|}{$55-90$} & \multirow{2}{*}{$\begin{array}{l}\Sigma \text { del } \\
\text { área } \\
\left(\mathrm{km}^{2}\right)\end{array}$} & \multirow{2}{*}{$\%$} \\
\hline Altitudinales & Área & $\%$ & Área & $\%$ & Área & $\%$ & Área & $\%$ & Área & $\%$ & Área & $\%$ & Área & $\%$ & & \\
\hline $45-80 m$ & 94.5 & 95.1 & 1.9 & 1.9 & 1.7 & 1.7 & 0.6 & 0.6 & 0.7 & 0.7 & 0.03 & 0.00 & 0.00 & 0.00 & 99.4 & 51.7 \\
\hline $80-120 m$ & 64.9 & 33.8 & 4.0 & 2.1 & 2.4 & 1.2 & 0.7 & 0.4 & 0.5 & 0.3 & 0.03 & 0.00 & 0.00 & 0.00 & 72.5 & 37.7 \\
\hline $120-200 \mathrm{~m}$ & 6.6 & 3.4 & 5.6 & 2.9 & 4.3 & 2.2 & 1.0 & 0.5 & 0.8 & 0.4 & 0.19 & 0.10 & 0.01 & 0.01 & 18.5 & 9.6 \\
\hline $200-260 \mathrm{~m}$ & 0.5 & 0.3 & 0.3 & 0.1 & 0.4 & 0.2 & 0.2 & 0.1 & 0.3 & 0.1 & 0.02 & 0.00 & 0.00 & 0.00 & 1.7 & 0.9 \\
\hline
\end{tabular}

Fuente: Elaborada por los autores.

Con posterioridad dentro de cada una de las cuatro localidades, se estudió la distribución de las pendientes (Tabla 2) y los rasgos morfológicos del territorio y mediante el cruce de estas variables quedaron establecidas 14 unidades de segundo orden denominadas como comarcas.

Se realizó la selección de los rangos para definir las geoformas del relieve. Se marcan con tonos de colores los rangos que conformarán las unidades morfológicas del relieve. Reagrupando estas combinaciones es posible obtener un agrupamiento de las unidades que presentan características homogéneas en cuanto a altimetría y pendiente (véase Tabla 4). 
Tabla 4

Análisis de los cruzamientos entre pisos altitudinales e intervalos de inclinación de las pendientes para la obtención de las unidades morfológicas

Primer criterio (intervalos)

\begin{tabular}{|c|c|c|c|c|c|c|c|c|c|c|c|c|c|c|c|c|}
\hline \multicolumn{17}{|c|}{ Inclinación de las pendientes $\left({ }^{\circ}\right)$} \\
\hline Pisos & \multicolumn{2}{|c|}{$0-3$} & \multicolumn{2}{|c|}{$3-5$} & \multicolumn{2}{|c|}{$5-10$} & \multicolumn{2}{|c|}{$10-15$} & \multicolumn{2}{|c|}{$15-35$} & \multicolumn{2}{|c|}{$35-55$} & \multicolumn{2}{|c|}{$55-90$} & \multirow{2}{*}{$\begin{array}{l}\Sigma \text { del } \\
\text { área } \\
\left(\mathrm{km}^{2}\right)\end{array}$} & \multirow{2}{*}{$\%$} \\
\hline Altitudinales & Área & $\%$ & Área & $\%$ & Área & $\%$ & Área & $\%$ & Área & $\%$ & Área & $\%$ & Área & $\%$ & & \\
\hline $\begin{array}{c}\text { Llanuras } \\
\text { medias } \\
45-80 \mathrm{~m}\end{array}$ & 94.5 & 95.1 & 1.9 & 1.9 & 1.7 & 1.7 & 0.6 & 0.6 & 0.7 & 0.7 & 0.03 & 0.00 & 0.00 & 0.00 & 99.4 & 51.7 \\
\hline $\begin{array}{c}\text { Llanuras altas } \\
80-120 \mathrm{~m}\end{array}$ & 64.9 & 33.8 & 4.0 & 2.1 & 2.4 & 1.2 & 0.7 & 0.4 & 0.5 & 0.3 & 0.03 & 0.00 & 0.00 & 0.00 & 72.5 & 37.7 \\
\hline Llanuras & 159.4 & 83.0 & 5.9 & 3.1 & 4.1 & 2.1 & 1.3 & 0.7 & 1.2 & 0.6 & 0.06 & 0.00 & 0.00 & 0.00 & 171.9 & 89.4 \\
\hline $\begin{array}{c}\text { Alturas bajas } \\
120-200 \mathrm{~m}\end{array}$ & 6.6 & 3.4 & 5.6 & 2.9 & 4.3 & 2.2 & 1.0 & 0.5 & 0.8 & 0.4 & 0.19 & 0.10 & 0.01 & 0.01 & 18.5 & 9.6 \\
\hline $\begin{array}{l}\text { Alturas medias } \\
200-260 \mathrm{~m}\end{array}$ & 0.5 & 0.3 & $|0.3|$ & 0.1 & 0.4 & 0.2 & 0.2 & 0.1 & 0.3 & 0.1 & 0.02 & 0.00 & 0.00 & 0.00 & 1.7 & 0.9 \\
\hline Alturas & 7.1 & 3.7 & 5.9 & 3.1 & 4.7 & 2.4 & 1.2 & 0.6 & 1.1 & 0.6 & 0.21 & 0.1 & 0.01 & 0.01 & 20.2 & 10.5 \\
\hline $\begin{array}{c}\Sigma \text { del área } \\
\left(\mathrm{km}^{2}\right)\end{array}$ & 166.5 & 86.7 & 11.8 & 6.1 & 8.8 & 4.5 & 2.5 & 1.3 & 2.3 & 1.2 & 0.27 & 0.10 & 0.01 & 0.01 & 192.1 & 50.2 \\
\hline
\end{tabular}

Segundo criterio (intervalos)

\begin{tabular}{|c|c|c|c|c|c|c|c|c|c|c|c|c|c|c|c|c|}
\hline \multicolumn{17}{|c|}{ Inclinación de las pendientes $\left({ }^{\circ}\right)$} \\
\hline Pisos & \multicolumn{2}{|c|}{$0-3$} & \multicolumn{2}{|c|}{$3-5$} & \multicolumn{2}{|c|}{$5-10$} & \multicolumn{2}{|c|}{$10-15$} & \multicolumn{2}{|c|}{$15-35$} & \multicolumn{2}{|c|}{$35-55$} & \multicolumn{2}{|c|}{$55-90$} & \multirow{2}{*}{$\begin{array}{l}\text { del } \\
\text { área } \\
\left(\mathrm{km}^{2}\right) \\
\end{array}$} & \multirow{2}{*}{$\%$} \\
\hline Altitudinales & Área & $\%$ & Área & $\%$ & Área & $\%$ & Área & $\%$ & Área & $\%$ & Área & $\%$ & Área & $\%$ & & \\
\hline $\begin{array}{c}\text { Llanuras } \\
\text { medias } \\
45-80 \mathrm{~m}\end{array}$ & 94.5 & 95.1 & 1.9 & 1.9 & 1.7 & 1.7 & 0.6 & 0.6 & 0.7 & 0.7 & 0.03 & 0.00 & 0.00 & 0.00 & 99.4 & 51.7 \\
\hline $\begin{array}{c}\text { Llanuras altas } \\
80-120 \mathrm{~m}\end{array}$ & 64.9 & 33.8 & 4.0 & 2.1 & 2.4 & 1.2 & 0.7 & 0.4 & 0.5 & 0.3 & 0.03 & 0.00 & 0.00 & 0.00 & 72.5 & 37.7 \\
\hline Llanuras & 159.4 & 83.0 & 5.9 & 3.1 & 4.1 & 2.1 & 1.3 & 0.7 & 1.2 & 0.6 & 0.06 & 0.00 & 0.00 & 0.00 & 171.9 & 89.4 \\
\hline $\begin{array}{c}\text { Alturas bajas } \\
120-200 \mathrm{~m}\end{array}$ & 6.6 & 3.4 & 5.6 & 2.9 & 4.3 & 2.2 & 1.0 & 0.5 & 0.8 & 0.4 & 0.19 & 0.10 & 0.01 & 0.01 & 18.5 & 9.6 \\
\hline $\begin{array}{c}\text { Alturas medias } \\
200-260 \mathrm{~m}\end{array}$ & 0.5 & 0.3 & 0.3 & 0.1 & 0.4 & 0.2 & 0.2 & 0.1 & 0.3 & 0.1 & 0.02 & 0.00 & 0.00 & 0.00 & 1.7 & 0.9 \\
\hline Alturas & 7.1 & 3.7 & 5.9 & 3.1 & 4.7 & 2.4 & 1.2 & 0.6 & 1.1 & 0.6 & 0.21 & 0.1 & 0.01 & 0.01 & 20.2 & 10.5 \\
\hline $\begin{array}{c}\Sigma \text { del área } \\
\left(\mathrm{km}^{2}\right)\end{array}$ & 166.5 & 86.7 & 11.8 & 6.1 & 8.8 & 4.5 & 2.5 & 1.3 & 2.3 & 1.2 & 0.27 & 0.10 & 0.01 & 0.01 & $\mid$\begin{tabular}{|l|} 
\\
$\mid$
\end{tabular} & 50.2 \\
\hline
\end{tabular}

Fuente: Elaborada por los autores. 


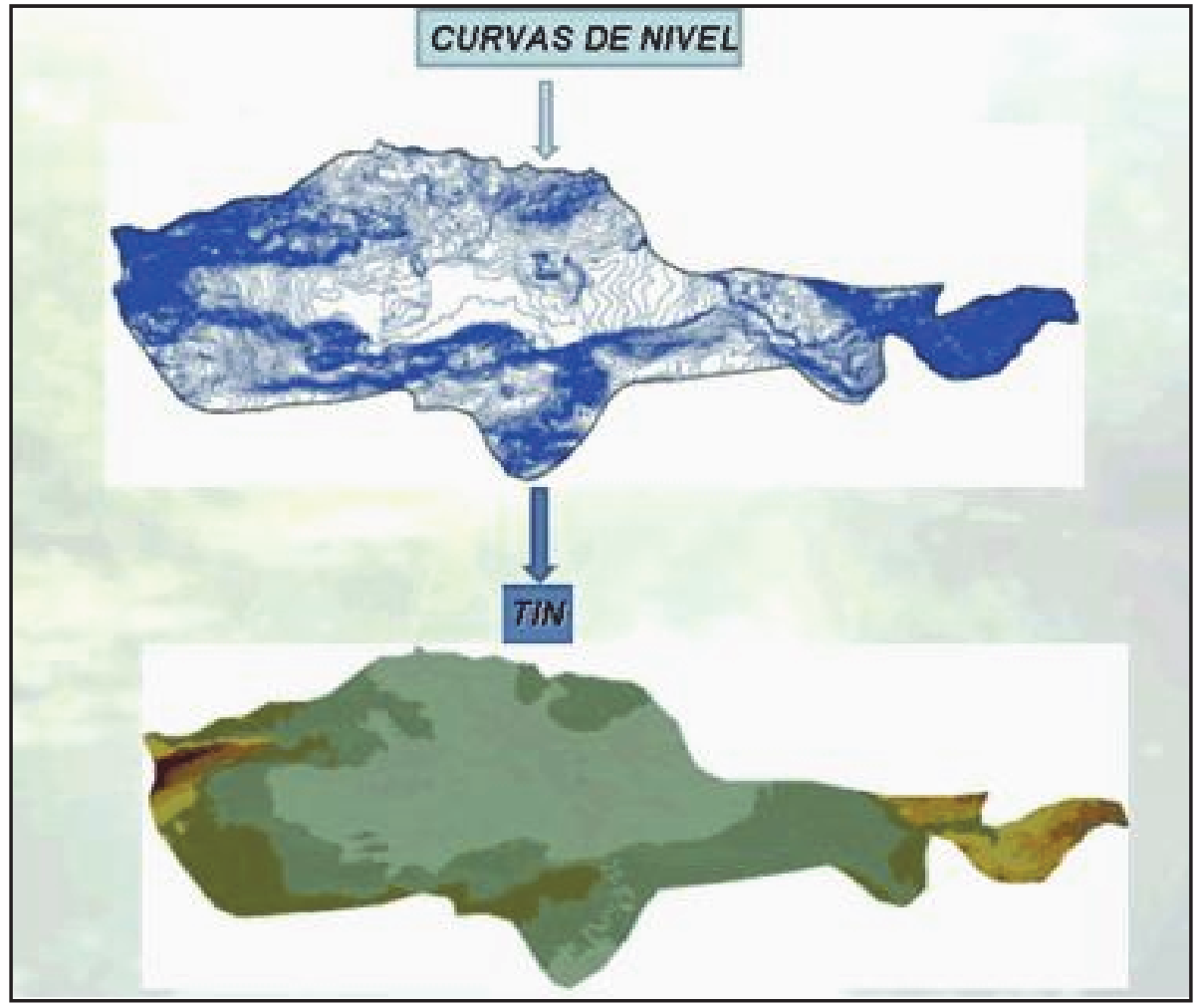

Figura 3. Obtención del Modelo TIN.

Fuente: Elaboración propia. 


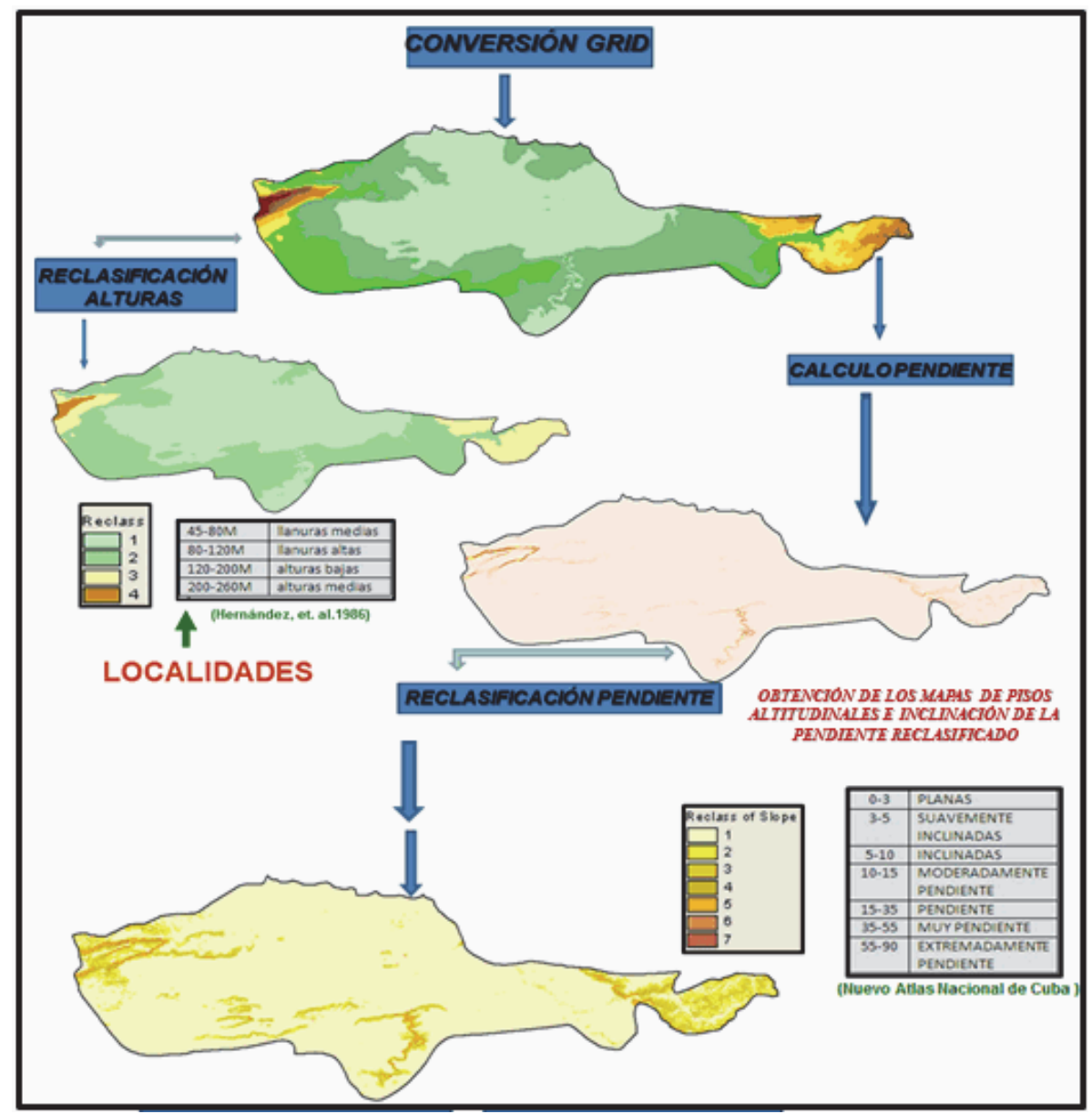

Figura 4. Obtención de los mapas de los pisos altitudinales e inclinación de la pendiente reclasificados.

Fuente: Elaboración propia. 


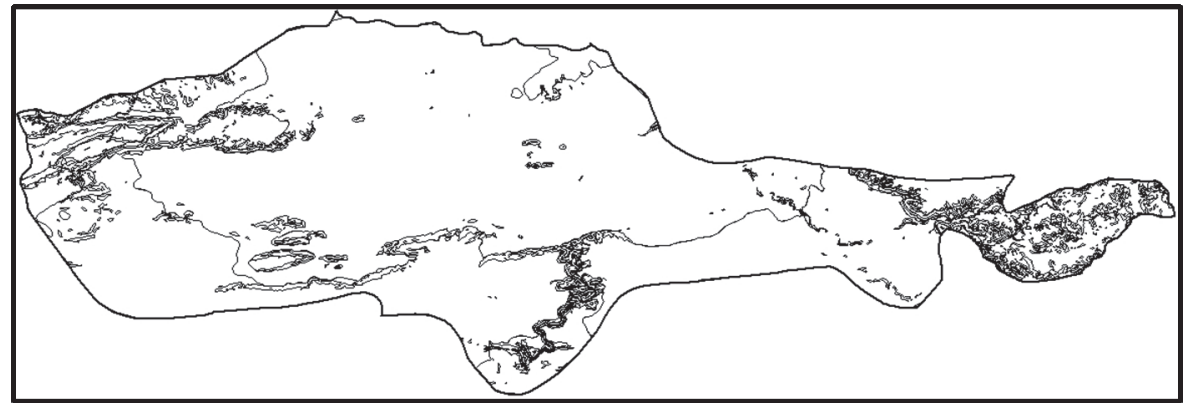

Figura 5. Comarcas (unidades morfológicas).

Fuente: Elaboración propia.

A partir de este reagrupamiento se obtienen las unidades morfológicas (Figura 5).

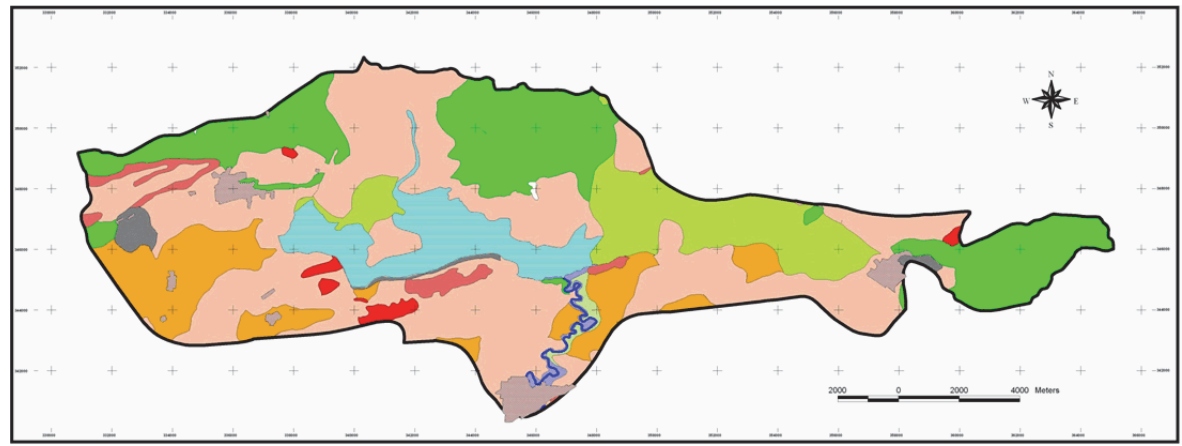

\section{LEYENDA}

\section{Subtipos de Carso}

Área no estudiada

Áreas no cársicas

Carso cubierto por depósitos potentes

Carso cubierto por una delgada capa de suelo

Carso desnudo

Carso desnudo (paracarso)

Carso desnudo y semidesnudo

Carso estabilizado

Asentamientos

Límite Cuenca Ariguanabo

Río Ariguanabo

Laguna Ariguanabo

Planos de inundación

Río San Antonio

Figura 6. Mapa de subtipo de carso (subcomarcas).

Fuente: Elaboración propia. 


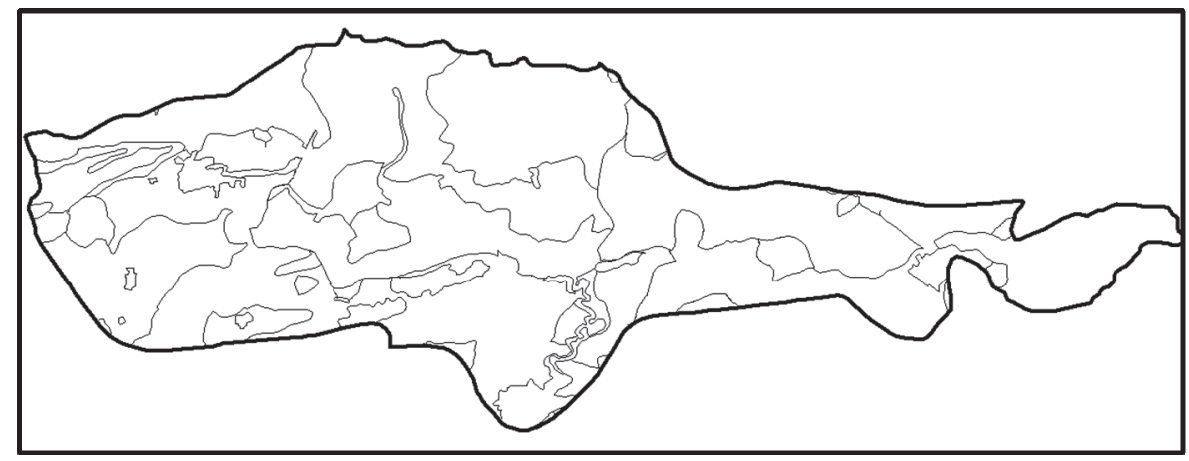

Figura 7. Mapa preliminar de paisajes (localidades, comarcas y subcomarcas). Fuente: Elaboración propia.
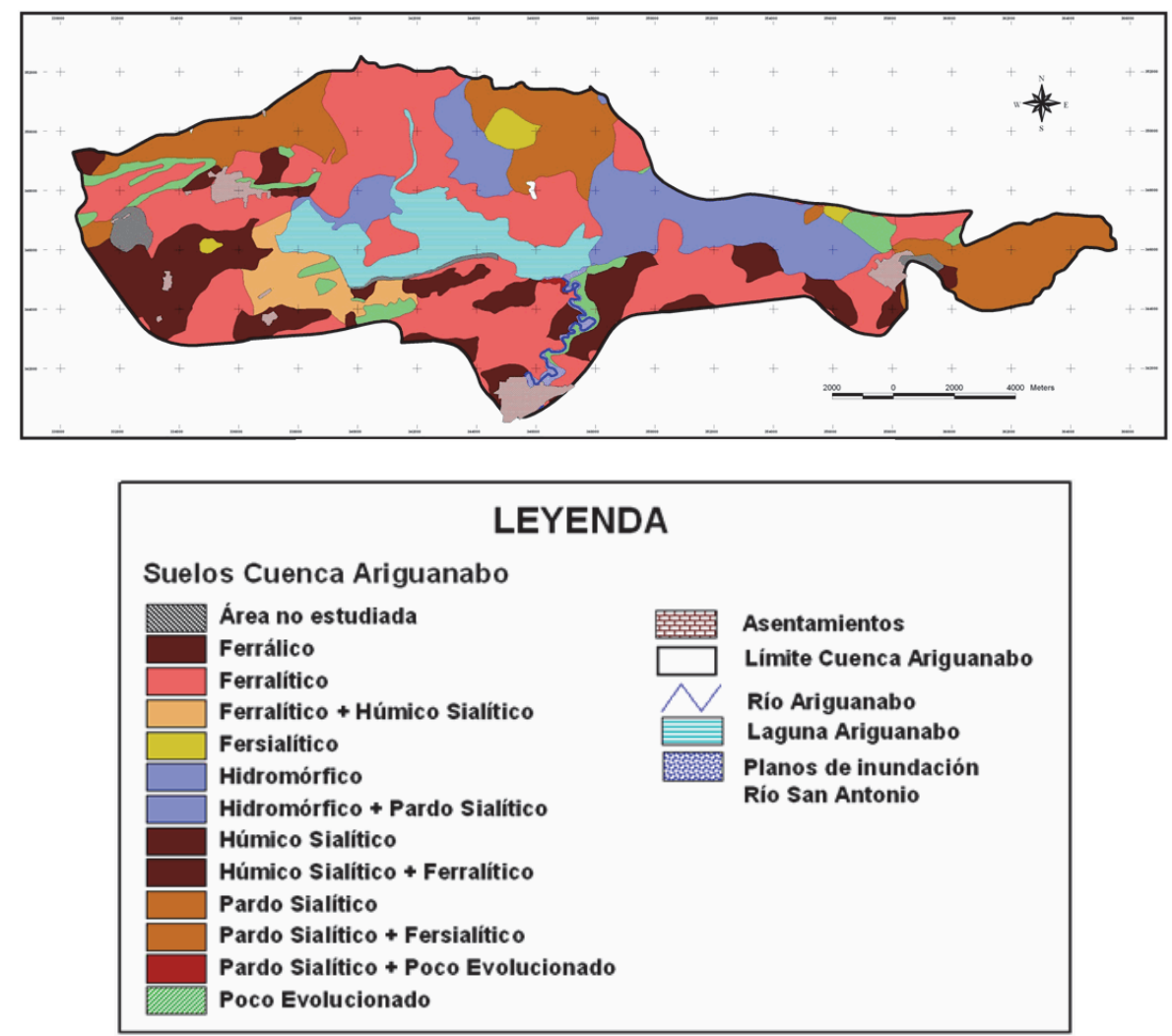

Figura 8. Mapa de suelos.

Fuente: Elaboración propia. 

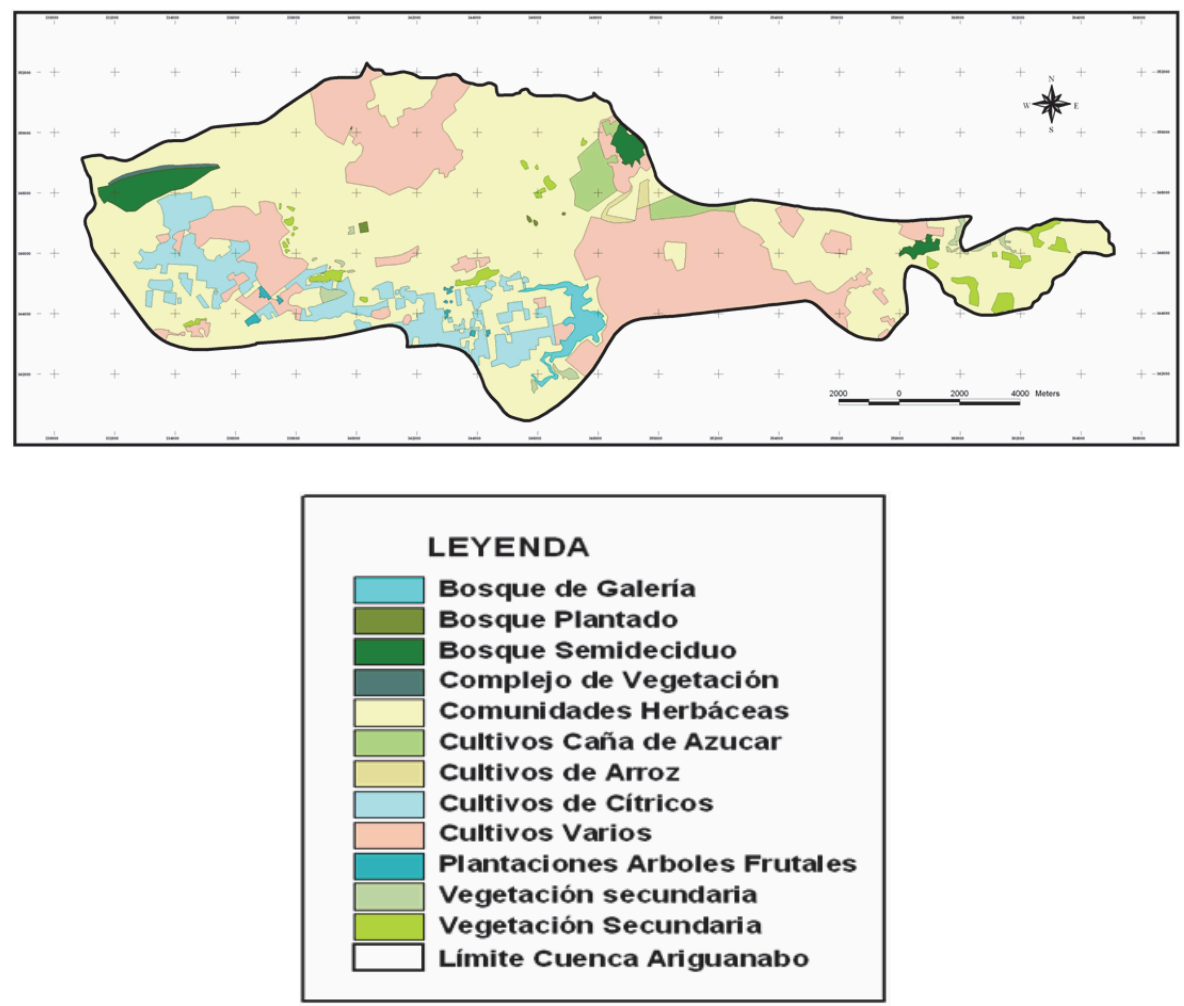

Figura 9. Mapa vegetación/uso.

Fuente: Elaboración propia.

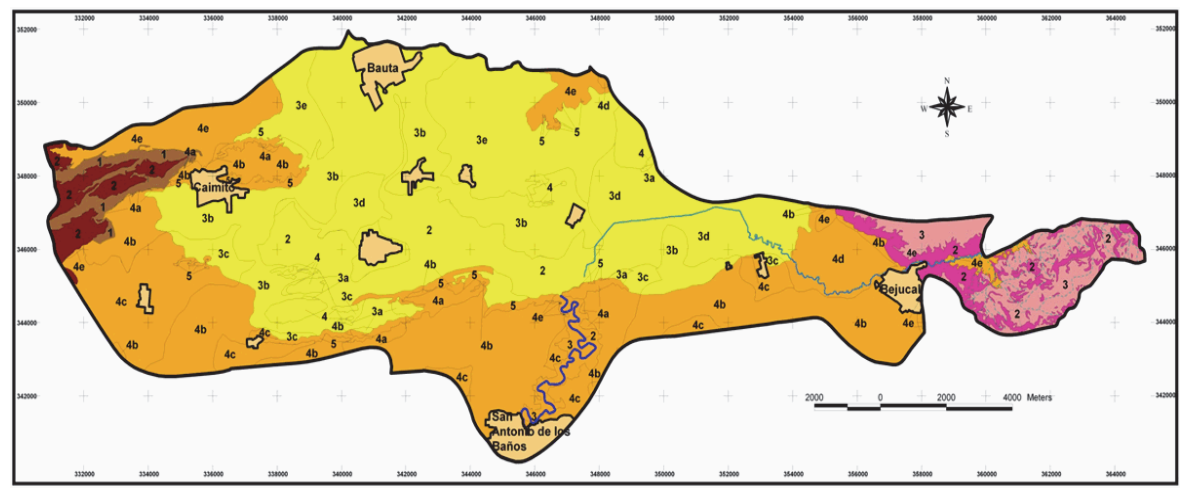

Figura 10. Mapa de paisajes de la cuenca Ariguanabo. 


\section{Continuación Figura 10 (leyenda explicativa del Mapa de paisajes de la cuenca Ariguanabo)}

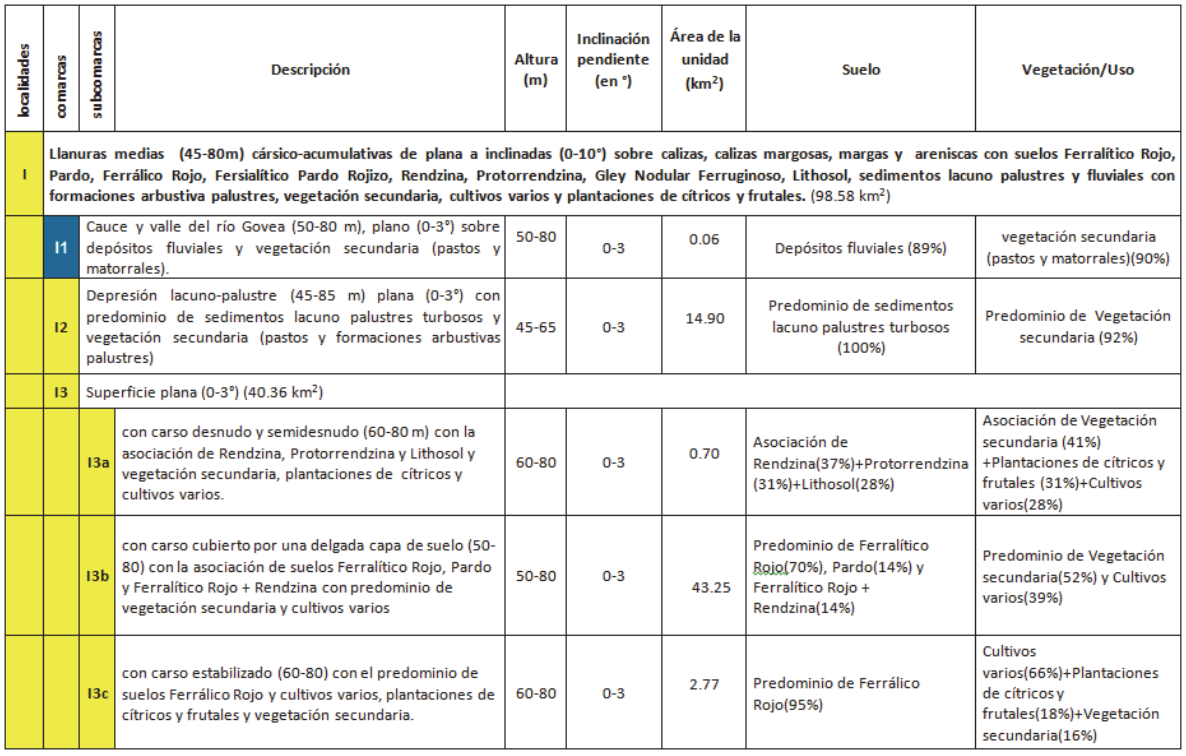

\begin{tabular}{|c|c|c|c|c|c|c|c|c|}
\hline 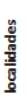 & है & 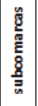 & Descripción & $\begin{array}{c}\text { Altura } \\
(\mathrm{m})\end{array}$ & $\begin{array}{l}\text { Inclinación } \\
\text { pendiente } \\
\left(\text { en }^{\circ}\right)\end{array}$ & $\begin{array}{c}\text { Área de la } \\
\text { unidad } \\
\left(\mathrm{km}^{2}\right)\end{array}$ & Suelo & Vegetación/Uso \\
\hline & & $13 \mathrm{~d}$ & $\begin{array}{l}\text { con carso cubierto por depósitos potentes (50-80) con } \\
\text { la asociación de suelos Gley Nodular Ferruginoso + } \\
\text { Pardo y Gley Nodular Ferruginoso con cultivos varios y } \\
\text { vegetación secundaria. }\end{array}$ & $50-80$ & $0-3$ & 16.15 & $\begin{array}{l}\text { Predominio de Gley Nodular } \\
\text { Ferruginoso + Pardo(80\%) y } \\
\text { Gley Nodular Ferruginoso(16\%) }\end{array}$ & $\begin{array}{l}\text { Cultivos } \\
\text { varios }(45 \%)+\text { Vegetación } \\
\text { secundaria(39\%) }\end{array}$ \\
\hline & & $13 e$ & $\begin{array}{l}\text { no cársica }(50-80) \text { plana }\left(0-3^{\circ}\right) \text { con la asociación de } \\
\text { suelos Pardo + Fersialítico Pardo Rojizo, Gley Nodular } \\
\text { Ferruginoso y Pardo con predominio de vegetación } \\
\text { secundaria. }\end{array}$ & $50-90$ & $0-3$ & 18.68 & $\begin{array}{l}\text { Asociación de Pardo + } \\
\text { Fersialítico Pardo Rojizo(46\%) + } \\
\text { Gley Nodular } \\
\text { Ferruginoso(26\%)+ Pardo(19\%) }\end{array}$ & $\begin{array}{l}\text { Predominio de Vegetación } \\
\text { secundaria(80\%) }\end{array}$ \\
\hline & 14 & \multicolumn{2}{|r|}{$\begin{array}{l}\text { Colinas residuales cársicas }(60-90 \mathrm{~m}) \text { con laderas inclinadas } \\
\left(0-10^{\circ}\right) \text { y cimas redondeadas con predominio de la } \\
\text { asociación de Ferralítico Rojo + Rendzina y Lithosol y } \\
\text { vegetación secundaria. }\end{array}$} & 60-90 & $0-10$ & 2.07 & $\begin{array}{l}\text { Predominio de Ferralítico Rojo } \\
+ \text { Rendzina(52\%)+ } \\
\text { Lithosol(28\%) }\end{array}$ & $\begin{array}{l}\text { Predominio de Vegetación } \\
\text { secundaria(88\%) }\end{array}$ \\
\hline & 111 & $\begin{array}{l}\text { Cauc } \\
\text { depc } \\
\text { (arro }\end{array}$ & $\begin{array}{l}\text { ze y valle del río Govea }(80-110 \mathrm{~m}) \text {, plano }\left(0-3^{\circ}\right) \text { sobre } \\
\text { ósitos fluviales y vegetación secundaria y cultivos varios } \\
\text { zz). }\end{array}$ & $80-110$ & $0-3$ & 0.07 & $\begin{array}{l}\text { Depósitos fluviales (82\%) y } \\
\text { suelos Pardos }(14 \%)\end{array}$ & $\begin{array}{l}\text { Predominio de Vegetación } \\
\text { secundaria(73\%)+Cultivos } \\
\text { varios }(22 \%)\end{array}$ \\
\hline & 112 & $\begin{array}{l}\text { Cauc } \\
\text { cauc } \\
\text { en } \\
\text { asoc } \\
\text { pred } \\
\text { vege }\end{array}$ & $\begin{array}{l}\text { y cañón del río Ariguanabo }(50-70 \mathrm{~m}) \text {, plano en el } \\
\left.\text { el co- } 3^{\circ}\right) \text { y de moderadamente pendiente a pendiente } \\
\text { el }\left(10-35^{\circ}\right) \text { sobre depósitos fluviales y la } \\
\text { iación de Lithosol, Ferrálico Rojo y Ferralítico Rojo con } \\
\text { dominio de bosque semideciduo poco alterado y } \\
\text { etación acuática en el cauce. }\end{array}$ & $50-70$ & $0-35$ & 0.55 & $\begin{array}{l}\text { Asociación de } \\
\text { Lithosol(40\%)+Ferralítico } \\
\text { Rojo(25\%)+Pardo + } \\
\text { Protorendzina(15\%)+Depósitos } \\
\text { fluviales }(17 \%)\end{array}$ & $\begin{array}{l}\text { Predominio de Bosque } \\
\text { semideciduo(84\%) y } \\
\text { vegetación acuática (14\%) }\end{array}$ \\
\hline
\end{tabular}


Continuación Figura 10 (leyenda explicativa del Mapa de paisajes de la cuenca Ariguanabo)

\begin{tabular}{|c|c|c|c|c|c|c|c|c|}
\hline 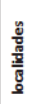 & 施 & 施 & Descripción & $\begin{array}{c}\text { Altura } \\
(\mathrm{m})\end{array}$ & $\begin{array}{l}\text { Inclinación } \\
\text { pendiente } \\
\left(\mathrm{en}{ }^{\circ}\right)\end{array}$ & $\begin{array}{c}\text { Área de la } \\
\text { unidad } \\
\left(\mathbf{k m}^{2}\right)\end{array}$ & Suelo & Vegetación/Uso \\
\hline & 113 & \multicolumn{2}{|r|}{$\begin{array}{l}\text { Laderas y zona de transición del Rio Ariguanabo }(60-90 \mathrm{~m}) \\
\text { de plana a inclinada }\left(0-10^{\circ}\right) \text { en la zona de transición y de } \\
\text { moderadamente pendiente a pendiente en las laderas }(10- \\
\left.35^{\circ}\right) \text { con la asociación de suelos Lithosol, Ferrálico Rojo y } \\
\text { Ferralítico Rojo y predominio de bosque semideciduo } \\
\text { medianamente degradado. }\end{array}$} & $60-90$ & $0-35$ & 33.85 & $\begin{array}{l}\text { Asociación de } \\
\text { Lithosol(36\%)+Ferrálico } \\
\text { Rojo(35\%)+Ferralítico } \\
\text { Rojo(23\%) }\end{array}$ & $\begin{array}{l}\text { Predominio de Bosque } \\
\text { semideciduo(96\%) }\end{array}$ \\
\hline & 114 & \multicolumn{2}{|c|}{ Superficie plana $\left(0-3^{\circ}\right)\left(63.67 \mathrm{~km}^{2}\right)$} & & & & & \\
\hline & & $\begin{array}{c}114 \\
\text { a }\end{array}$ & $\begin{array}{l}\text { con carso desnudo y semidesnudo }(80-110 \mathrm{~m}) \text { con } \\
\text { asociación de Rendzina, Protorrendzina y Lithosol y } \\
\text { predominio de vegetación secundaria y cultivos varios. }\end{array}$ & $80-110$ & $0-3$ & 2.33 & $\begin{array}{l}\text { Asociación de } \\
\text { Rendzina(45\%)+Protorrendzina } \\
(37 \%)+\text { Lithosol( } 15 \%)\end{array}$ & $\begin{array}{l}\text { Predominio de Vegetación } \\
\text { secundaria(72\%) y Cultivos } \\
\text { varios(16\%) }\end{array}$ \\
\hline & & $\begin{array}{c}114 \\
\text { c }\end{array}$ & $\begin{array}{l}\text { con carso estabilizado }(80-120 \mathrm{~m}) \text { con predominio de } \\
\text { los suelos Ferrálico Rojo y la asociación de vegetación } \\
\text { secundaria, cultivos varios y plantaciones de cítricos y } \\
\text { frutales. }\end{array}$ & $80-120$ & $0-3$ & 17.03 & $\begin{array}{l}\text { Predominio de Ferrálico } \\
\text { Rojo(95\%) }\end{array}$ & $\begin{array}{l}\text { Asociación de Vegetación } \\
\text { secundaria(47\%)+Cultivos } \\
\text { varios }(31 \%)+\text { Cultivos de } \\
\text { cítricos }(21 \%)\end{array}$ \\
\hline & & $\begin{array}{c}114 \\
d\end{array}$ & $\begin{array}{l}\text { carso cubierto por depósitos potentes }(80-100 \mathrm{~m}) \text { con } \\
\text { predominio de la asociación de suelos Gley Nodular } \\
\text { Ferruginoso + Pardo y predominio de vegetación } \\
\text { secundaria y cultivos varios. }\end{array}$ & $80-100$ & $0-3$ & 5.00 & $\begin{array}{l}\text { Predominio de Gley Nodular } \\
\text { Ferruginoso + Pardo }(99 \%)\end{array}$ & $\begin{array}{l}\text { Predominio de Vegetación } \\
\text { secundaria(84\%)+Cultivos } \\
\text { varios(16\%) }\end{array}$ \\
\hline & & $\begin{array}{c}114 \\
\text { e }\end{array}$ & $\begin{array}{l}\text { no cársica }(80-120 \mathrm{~m}) \text { con la asociación de suelos } \\
\text { Pardo + Fersialítico Pardo Rojizo y predominio de } \\
\text { vegetación secundaria y cultivos varios. }\end{array}$ & $80-120$ & $0-3$ & 2.11 & $\begin{array}{l}\text { Predominio de Pardo + } \\
\text { Fersialítico Pardo Rojizo(86\%) }\end{array}$ & $\begin{array}{l}\text { Predominio de Vegetación } \\
\text { secundaria(100\%) }\end{array}$ \\
\hline
\end{tabular}

\begin{tabular}{|c|c|c|c|c|c|c|c|}
\hline 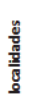 & 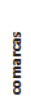 & 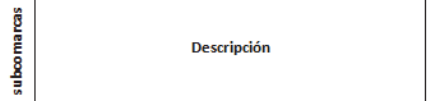 & $\begin{array}{c}\text { Altura } \\
(\mathrm{m})\end{array}$ & $\begin{array}{l}\text { Inclinación } \\
\text { pendiente } \\
(\mathrm{en})^{\circ}\end{array}$ & $\begin{array}{c}\text { Área de la } \\
\text { unidad } \\
\left(\mathrm{km}^{2}\right)\end{array}$ & Suelo & Vegetación/Uso \\
\hline & 115 & $\begin{array}{l}\text { Superficie de transición }(60-130 \mathrm{~m}) \text {, escalón suavemente } \\
\text { inclinado a inclinado }\left(3-10^{\circ}\right) \text { con suelos Ferralítico Rojo, } \\
\text { Ferrálico Rojo, Lithosol, Rendzina y Protorendzina con } \\
\text { predominio de vegetación secundaria, cultivos varios y } \\
\text { plantaciones de cítricos y frutales. }\end{array}$ & $60-130$ & $3-10$ & 3.45 & $\begin{array}{l}\text { Asociación de Ferralítico } \\
\text { Rojo(24\%)+Ferrálico } \\
\text { Rojo(18\%)+Lithosol(18\%)+Ren } \\
\text { dzina(13\%)+Protorenzina(8\%) }\end{array}$ & $\begin{array}{l}\text { Predominio de Vegetación } \\
\text { secundaria(78\%), Cultivos } \\
\text { varios }(9 \%) \text { y Plantaciones } \\
\text { de cítricos y frutales }(9 \%)\end{array}$ \\
\hline
\end{tabular}

III Alturas bajas estructuro-denudativas y erosivas $(\mathbf{1 2 0 - 2 0 0} \mathrm{m})$ predominantemente sobre margas, con suelos Pardo, Ferralítico Rojo y Lithosol con vegetación III secundaria y restos de bosque semideciduo degradado. $\left(15.01 \mathrm{~km}^{2}\right)$

\begin{tabular}{|c|l|c|c|c|l|l|}
\hline III1 & $\begin{array}{l}\text { Cañadas intermitentes de primer y segundo orden }(120-160 \\
\text { m)de suavemente inclinadas a moderadamente pendientes } \\
\left(3-15^{\circ}\right)\end{array}$ & $\begin{array}{c}120- \\
160\end{array}$ & $3-15$ & 0.08 & $\begin{array}{l}\text { Predominio de } \\
\text { Pardo(45\%)+Lithosol(30\%) }\end{array}$ & $\begin{array}{l}\text { Predominio de Vegetación } \\
\text { secundaria arbustiva }(90 \%)\end{array}$ \\
\hline III2 & $\begin{array}{l}\text { Laderas }(90-190 \mathrm{~m}) \text { inclinadas }\left(5-10^{\circ}\right) \text { con suelos Pardo y } \\
\text { Lithosol y predominio de vegetación secundaria. }\end{array}$ & $90-190$ & $3-10$ & 5.65 & $\begin{array}{l}\text { Predominio de } \\
\text { Pardo(68\%)+Lithosol(18\%) }\end{array}$ & $\begin{array}{l}\text { Predominio de Vegetación } \\
\text { secundaria(93\%) }\end{array}$ \\
\hline III3 & $\begin{array}{l}\text { Cimas }(120-200 \mathrm{~m}) \text { de plana a suavemente inclinadas }\left(0-5^{\circ}\right) \\
\text { con suelos Pardo y Ferralítico Rojo y predominio de } \\
\text { vegetación secundaria }\end{array}$ & $\begin{array}{c}120- \\
200\end{array}$ & $0-5$ & 9.28 & $\begin{array}{l}\text { Predominio de Pardo(75\%) y } \\
\text { Ferralítico Rojo(19\%) }\end{array}$ & $\begin{array}{l}\text { Vegetación } \\
\text { secundaria(92\%) }\end{array}$ \\
\hline
\end{tabular}

Alturas medias estructuro-cársicas $(\mathbf{1 2 0}-\mathbf{2 6 0 \mathrm { m } )}$ sobre calizas y calizas margosas, con suelos Ferralítico Rojo, Pardo y Lithosol con Vegetación secundaria y Bosque semideciduo y matorral arbustivo. $\left(7.25 \mathrm{~km}^{2}\right)$

\begin{tabular}{|c|l|l|l|l|l|l|}
\hline IV1 & $\begin{array}{l}\text { Escarpes }(80-230 \mathrm{~m}) \text { de inclinados a pendientes }\left(5-35^{\circ}\right) \text { con } \\
\text { predominio de Lithosol y Ferralítico Rojo y vegetación } \\
\text { secundaria y bosque semideciduo medianamente } \\
\text { degradado. }\end{array}$ & $80-230$ & $5-35$ & 3.27 & $\begin{array}{l}\text { Predominio de Lithosol(51\%) y } \\
\text { Ferralítico Rojo(31\%) }\end{array}$ & $\begin{array}{l}\text { Predominio de Vegetación } \\
\text { secundaria(58\%) y Bosque } \\
\text { semideciduo(30\%) }\end{array}$ \\
\hline IV2 $\begin{array}{l}\text { Cimas }(110-260 \mathrm{~m}) \text { de plana a suavemente inclinadas }\left(0-5^{\circ}\right) \\
\text { con suelos Ferralítico Rojo, Pardo y Lithosol y predominio } \\
\text { de vegetación secundaria y bosque semideciduo } \\
\text { medianamente degradado }\end{array}$ & $\begin{array}{c}110- \\
260\end{array}$ & $0-5$ & 3.98 & $\begin{array}{l}\text { Predominio de Ferralítico } \\
\text { Rojo(56\%)+Pardo(18\%)+Lithos } \\
\text { ol (12\%) }\end{array}$ & $\begin{array}{l}\text { Predominio de Vegetación } \\
\text { secundaria(53\%)+Bosque } \\
\text { semideciduo(46\%) }\end{array}$ \\
\hline
\end{tabular}

Figura 10. Mapa de paisajes de la cuenca Ariguanabo. Fuente: Elaboración propia. 
Por último atendiendo a la presencia y grado de desarrollo de los procesos cársicos, evidenciados en la tipología del carso presente (Iturralde-Vinent, 1996; Morelio et al., 2001 e Instituto de Geofísica y Astronomía - IGA, 2012), se realizó el cruce entre el mapa de tipos de carso (subcomarcas) (Figura 6) y el de las unidades morfológicas (comarcas) (Figura 5), resultando la diferenciación de 10 nuevas entidades de tercer orden (nombradas subcomarcas). Dando como resultado el mapa con las unidades en su conjunto (localidades, comarca y subcomarcas) (Figura 7).

El mapa con las unidades en su conjunto (Figura 7) se cruzó con el mapa de tipo de suelo (Figura 8) y con el de la cubierta vegetal (Figura 9), lo cual permitió caracterizar cada una de las entidades por su componente edáfico y la vegetación o uso del suelo existente (Bastart, 1998; Capote et al. y Capote y Berazain, 2005), con lo cual se obtiene el mapa de paisajes de la cuenca (Figura 10).

Después, el mapa con las unidades en su conjunto (localidades, comarcas y subcomarcas) (Figura 7) se cruzó con el mapa de tipo de suelo (Figura 8) y con el de la cubierta vegetal (Figura 9), lo cual permitió caracterizar cada una de las entidades por su componente edáfico y la vegetación o uso del suelo existente (Bastart, 1998; Capote et al.; Capote y Berazain, 2005). Al final después de todo este proceso se obtuvo el mapa de paisajes de la cuenca Ariguanabo (Figura 10), con IV unidades a nivel de localidades que a continuación se detallan:

- Unidad I. Llanuras medias (45-80m) cársico-acumulativas de plana a inclinadas $\left(0-10^{\circ}\right)$ sobre calizas, calizas margosas, margas y areniscas con suelos ferralítico rojo, pardo, ferrálico rojo, fersialítico pardo rojizo, rendzina, protorrendzina, gley nodular ferruginoso, lithosol, sedimentos lacuno palustres y fluviales con formaciones arbustiva palustres, vegetación secundaria, cultivos varios y plantaciones de cítricos y frutales $\left(98.58 \mathrm{~km}^{2}\right)$.

- Unidad II. Llanuras altas (80-120m) cársica sobre calizas y margas, de plana a pendiente $\left(0-35^{\circ}\right)$, con suelos ferralítico rojo, pardo, rendzina, gley nodular ferruginoso, lithosol, fersialítico pardo rojizo y con vegetación secundaria, cultivos varios, plantaciones de cítricos y frutales, y bosque semideciduo con diverso grado de alteración y vegetación acuática asociada a los cauces permanentes $\left(66.69 \mathrm{~km}^{2}\right)$.

- Unidad III. Alturas bajas estructuro-denudativas y erosivas (120-200m) predominantemente sobre margas, con suelos pardo, ferralítico rojo y lithosol con vegetación secundaria y restos de bosque semideciduo degradado $\left(15.01 \mathrm{~km}^{2}\right)$.

- Unidad IV. Alturas medias estructuro-cársicas (120-260m) sobre calizas y calizas margosas, con suelos ferralítico rojo, pardo y lithosol con vegetación secundaria y bosque semideciduo y matorral arbustivo $\left(7.25 \mathrm{~km}^{2}\right)$. 


\section{Conclusiones}

1. Los estudios de integración geográfica en Cuba tienen una larga historia y han estado relacionados con el propio desarrollo de la Geografía como disciplina científica y los aportes realizados por diversos especialistas durante más de 100 años.

2. En las últimas décadas se ha consolidado este enfoque de integración dando lugar a la Escuela de Paisajes Cubana, que ha extendido la aplicación de esta concepción a los trabajos de ordenamiento ambiental y territorial no solo en nuestro país sino en otros países de América Latina.

3. El uso de los Sistemas de Información Geográfica y otras técnicas posibilitan realizar análisis más detallados y precisos sobre los paisajes como unidades de integración y su uso en diversas tareas de planificación y gestión territorial.

4. El uso de los SIG constituyó una valiosa herramienta para el manejo y procesamiento de la información de los diversos componentes (relieve, litología, suelo y vegetación/uso) posibilitando la delimitación, clasificación y cartografía de los paisajes a partir del empleo de índices diagnósticos previamente establecidos.

5. La clasificación de los pisos altimétricos utilizada en el Nuevo Altas Nacional de Cuba y el reconocimiento de los procesos formadores del relieve permitió la delimitación de cuatro unidades de primer orden (localidades) que posteriormente con el análisis de la altimetría e inclinación de la pendiente posibilitó dividir las unidades anteriores en 14 subunidades (comarcas) y finalmente la inclusión de los subtipos de carso como índices de diagnóstico en la diferenciación de las subunidades permitió delimitar 10 subcomarcas, lo cual resultó algo novedoso para nuestro país.

6. El Mapa de paisajes aquí presentado sienta las bases para la delimitación de las unidades ambientales de la cuenca Ariguanabo que servirán para la planificación territorial y ambiental.

\section{Bibliografía}

Acevedo, P., Análisis de los paisajes insulares del Archipiélago Sabana-Camagüey, (inédito), tesis de doctorado, Universidad de La Habana 1996, 130 pp.

Bastart, M., Diversidad vegetal de la Habana, Cuba, (inédito) tesis de maestría, Instituto de Ecología y Sistemática, La Habana, 1998, 61 pp.

Bastian, O. y Steinhardt, U., Development and Perspectives of Landscape Ecology, Kluwer Academic Publishers, Dordrecht, 2002, 498 pp.

Bertrand, C. y Bertrand, G., Geografia del medio ambiente. El Sistema GTP: Geosistema, Territorio y Paisaje, Universidad de Granada, 2006, 403 pp.

Busquets, J. y Cortina, A. (coords.), Gestión del Paisaje. Manual de protección, gestión y ordenación del paisaje, Editorial Ariel, Barcelona, 2009, 703 pp. 
Capote, R. et al., Formaciones vegetales. Mapa de vegetación actual de las provincias habaneras (Ciudad de La Habana y La Habana), Cuba, escala: 1:50,000, Instituto de Ecología y Sistemática, Agencia de Medio Ambiente, CITMA, 2006.

Capote, R. y Berazain, R., "Clasificación de las formaciones vegetales de Cuba", Revista del Jardín Botánico Nacional, vol. 2, núm. 2, pp. 12-34, La Habana, 1984.

Colectivo de autores, Nuevo Altas Nacional de Cuba, Instituto de Geografía, La Habana, 1989, 60 p.

Gaceta Oficial de la República de Cuba, núm. 7, Ley No. 81 del Medio Ambiente, La Habana, 11 de julio de 1997, 47 pp.

GAMMA, S.A, “Actualización del diagnóstico ambiental de la cuenca Ariguanabo, provincia La Habana”, (inédito), 2007, 91 pp.

Hernández, J.R.; Díaz, J.L.; Portela, A.H.; Blanco, P. y Magaz, A., Los principios básicos de la clasificación morfoestructural del relieve cubano, Editorial Academia de Ciencias de Cuba, La Habana, 1986, 60 pp.

IGA, "Indicadores para la evaluación del geopotencial del medio físico: una herramienta para la planificación ambiental territorial. Estudios de caso provincia Artemisa y municipio Moa”, (inédito), 2012.

Iturralde-Vinent, M., "Introduction to Cuban geology and tectonics, en ofiolitas y arcos volcánicos de Cuba", IUGS/Unesco, Project 364, Spec. Contr., vol. 1, pp. 3-35, Miami, USA, 1996.

Mateo, J., Aportes para la formulación de una teoría geográfica de la sostenibilidad ambiental, (inédito), tesis de doctor en Ciencias, Universidad de La Habana, 2007, 158 pp.

Mateo, J., Geografia de los paisajes, primera parte. Paisajes naturales, Editorial Universitaria, La Habana, 2008, 191 pp.

Mateo, J.; Salinas, E. y Guzmán, J.L., "El análisis de los paisajes como fundamento para la planificación de los territorios", Primera Jornada sobre Planificación Regional, y Urbana, IPF-JUCEPLAN, La Habana, 1985, 18 pp.

Mateo, J.; Salinas, E., Bollo, M. e Iñiguez, L., "Mapa de Paisajes de Cuba a escala 1:1,000,000”, Nuevo Atlas Nacional de Cuba, Instituto Geográfico Nacional de España, Madrid, 1989.

Molerio et al., "Protección ambiental y gestión integrada de los recursos hídricos superficiales y subterráneos de la cuenca Ariguanabo", (inédito), IGA, La Habana, 2001.

NC 93-06-101 "Paisaje. Términos y definiciones. Sistema de Normas para la Protección del Medio Ambiente", Comité Estatal de Normalización, La Habana, $1987,15 \mathrm{pp}$.

Oficina Nacional de Estadísticas (ONE), Anuario Estadístico de Cuba, 2011. 
Quintela, J., El inventario, el análisis y el diagnóstico geoecológico de los paisajes mediante el uso de los $\mathrm{SIG}$, (inédito), tesis de doctorado, Universidad de La Habana, 1995, $105 \mathrm{pp}$.

Ramón, A.; Salinas, E. y Remond, R., "Diseño metodológico para la elaboración de mapas de paisajes con el uso de los SIG: aplicación a la cuenca alta del río Cauto, Cuba", Geografia y Sistemas de Información Geográfica (GeoSIG), vol. 1, núm. 1, pp. 95-108, 2009.

Ramón, A.M. y Salinas, E., Guía para la elaboración de mapas de paisajes con el uso del ArcGIS. Metodología para la determinación de unidades de paisajes del nivel local con ArcGIS Desktop, Editorial Academia Española, Saarbrucken, Alemania, 2012, $98 \mathrm{pp}$.

Ramón, A. y Salinas, E., "Propuesta metodológica para la delimitación semiautomátizada de unidades de paisaje de nivel local", Revista do Departamento de Geografía, USP, núm. 25, pp. 3-22, 2013.

Remond, R., Degradación de los paisajes de Cuba, (inédito), tesis de doctorado, Universidad de La Habana, 2003, 105 pp.

Salitchev, K.A., Cartografía, Editorial Pueblo y Educación, La Habana, 1979, 182 pp. Salinas, E., Análisis y evaluación de los paisajes en la planificación regional en Cuba, (inédito), tesis de doctorado, Universidad de la Habana, 1991, 187 pp.

—_, "El ordenamiento geoecológico en la planificación regional en Cuba", Medio Ambiente y Urbanización, vol. 13, núm. 49, pp. 89-99, Buenos Aires, Argentina, 1994.

—_ "La Geografía y el Ordenamiento Territorial en Cuba", La Gaceta Ecológica, vol. 76, pp. 35-51, México, 2005.

Salinas, E. y Quintela, J., "Paisajes y Ordenamiento Territorial. Obtención del mapa de paisajes del Estado de Hidalgo en México a escala media con el apoyo de los SIG”, Alquibla, Revista de Investigaciones del Bajo Segura, núm. 7, pp. 517527, Alicante, España, 2000.

Salinas, E.; Mateo, J. y Machado, R., "Estudios geográficos y clasificación de los paisajes de Cuba, en Latinoamérica. Territorios y países en el umbral del siglo XXI", I Congreso Nacional de Geografía sobre Latinoamérica, pp. 401-411, Editorial MAPFRE América Tarragona, España, 1993. 